\title{
PAPER
}

\section{Uniquely human self-control begins at school age}

\section{Esther Herrmann, ${ }^{1}$ Antonia Misch, ${ }^{1}$ Victoria Hernandez-Lloreda ${ }^{2}$ and Michael Tomasello'}

1. Max Planck Institute for Evolutionary Anthropology, Leipzig, Germany

2. Department of Methodology for Behavioral Science, Universidad Complutense de Madrid, Spain

\begin{abstract}
Human beings have remarkable skills of self-control, but the evolutionary origins of these skills are unknown. Here we compare children at 3 and 6 years of age with one of humans' two nearest relatives, chimpanzees, on a battery of reactivity and selfcontrol tasks. Three-year-old children and chimpanzees were very similar in their abilities to resist an impulse for immediate gratification, repeat a previously successful action, attend to a distracting noise, and quit in the face of repeated failure. Sixyear-old children were more skillful than either 3-year-olds or chimpanzees at controlling their impulses. These results suggest that humans' most fundamental skills of self-control-as part of the overall decision-making process - are a part of their general great ape heritage, and that their species-unique skills of self-control begin at around the age at which many children begin formal schooling.
\end{abstract}

\section{Research highlights}

- The first study to investigate the evolutionary bases, as well as the developmental changes, of humans' self-regulatory skills.

- Broad comparison of children at 3 and 6 years of age with one of humans' two nearest relatives, chimpanzees, on a variety of reactivity and self-control tasks.

- Six-year-old children showed better self-control than either 3-year-old children or chimpanzees.

- The origins of human self-control lie within our general primate heritage, but uniquely human processes of self-control emerge roughly at school age.

\section{Introduction}

Human behavior is structured by cognition, but it is energized by the temperamental/motivational system. A number of studies have investigated the evolutionary roots of human cognition by comparing the cognitive skills of humans and other great apes (e.g. Herrmann, Call, Hernández-Lloreda, Hare \& Tomasello, 2007), and some studies have even done so across several years of human ontogeny (Wobber, Hare, Herrmann, Wrangham \& Tomasello, 2014). However, very few studies have investigated the evolutionary roots of human temperament (e.g. Herrmann, Hare, Cissewski \& Tomasello, 2011), and those that have done so have focused only on some specific dimensions and on single periods of human ontogeny.

Classically, temperament is thought to comprise two principal components: (1) reactivity, which can be defined as the characteristics of the individual's reaction to changes in the environment, and (2) self-regulation, defined as the ability to modulate reactivity (Rothbart \& Derryberry, 1981; Rothbart \& Bates, 2006). The first and more reactive dimension of temperament has been especially well researched, including studies on species ranging from insects to several mammals, including humans (Gosling 2001; Rothbart, Ahadi, Hershey \& Fisher, 2001; Réale, Reader, Sol, McDougall \& Dingemanse, 2007). Moreover, it has been hypothesized that human temperament may differ from that of other apes and that these differences are a prerequisite for the expression of more complex and unique forms of human 
cognition (Hare \& Tomasello 2005; Hare 2007). However, support for this hypothesis has come from research which did not directly investigate the temperament of apes but instead focused on possible constraints, like tolerance, on cooperative behavior (Hare, Melis, Woods, Hastings \& Wrangham, 2007; Melis, Hare \& Tomasello, 2006). There have been few studies investigating individual differences in reactivity in nonhuman apes, including approach-avoidance (shyness-boldness) tendencies in novel situations (see Freeman \& Gosling, 2010, for a review on nonhuman primate personality; Glickman \& Sroges, 1966; Parker, 1974; Torigoe, 1985; Yerkes \& Yerkes, 1936; Hebb, 1949; Lilienfeld, Gershon, Duke, Marino \& de Waal, 1999; Massen, Antonides, Arnold, Bionda \& Koski, 2013; also see Uher, Asendorpf \& Call, 2008). Humans display marked individual differences in their shyness-boldness. These differences emerge early in infancy and persist, remaining relatively stable throughout ontogeny (Kagan, 1997; Rothbart, Derryberry \& Hershey, 2000; Kagan \& Snidman, 2004). In a recent study, Herrmann et al. (2011) directly compared the reactivity of human and nonhuman apes. 2.5-year-old children showed a shyer temperamental profile than the other apes, which was hypothesized to promote children seeking reassurance from their parents and peers in a way that likely provides a species-unique opportunity for social learning and teaching. This more shy and therefore possible observant stance likely helps children to reflect on what causes the behavior of others, which in turn leads to more sophisticated social cognitive abilities later in life (Wellman, Lane, LaBounty \& Olson, 2011).

The second important dimension of temperament is the more active dimension concerning how organisms self-regulate and control their behavior. In contrast to the more reactive tendencies towards changes in the environment, which are presumed to be involuntary, automatic, and can be observed very early in life (Kagan \& Snidman, 2004; Posner \& Rothbart, 2000), selfregulation is assumed to be voluntary and to develop gradually during childhood, with an increase between 3 and 5 years of age, and may even continue to develop into adulthood (Posner \& Rothbart, 2000; Kopp, 1989; Kopp \& Neufeld, 2003; Murphy, Eisenberg, Fabes, Shepard \& Guthrie, 1999). Some of the terms used for these skills of self-regulation by researchers from various disciplines are: 'executive function', 'conscientiousness', 'emotion-related regulation', and 'self-control' (Baumeister \& Heatherton, 1996; Diamond, 2013; Eisenberg \& Morris, 2002; Jackson, Bogg, Walton, Wood, Harms et al., 2009; Rothbart \& Bates, 2006; Rothbart \& Derryberry, 1981). Some researchers also use the term effortful control, which includes the ability to inhibit a dominant response while activating a subdominant response, voluntarily focusing and shifting attention, and the ability to make decisions in the presence of conflicting stimuli (Rothbart \& Bates, 2006; Zhou, Chen \& Main, 2012). Inhibitory control and attentional control, two main abilities of the self-regulatory concept, will be the focus of this study.

A common method used in infant and child development studies investigating effortful control is using questionnaires. In recent years there have been several studies which used behavioral measures to investigate one of the components of effortful control (e.g. Mischel \& Ayduk, 2004; Eisenberg, Guthrie, Fabes, Reiser, Murphy et al., 1997) as well as a comprehensive test battery capturing effortful control (Kochanska, Murray, Jacques, Koenig \& Vandegeest, 1996; Kochanska, Murray \& Coy, 1997; Kochanska, Murray \& Harlan, 2000; Carlson \& Moses, 2001; Carlson, Moses \& Claxton, 2004) with a special interest in investigating the relationship between effortful control, social competence, moral behavior and social cognition. A number of studies found strong correlations between children's performance on tasks which required inhibitory control and shifting attention and their performance on classic false belief tasks (e.g. Carlson \& Moses, 2001; Carlson et al., 2004; Hala, Hug \& Henderson, 2003; Perner, Lang \& Kloo, 2002). This connection presumably exists because comprehending that a person falsely believes that an object is in location $\mathrm{X}$ requires the child to in some sense inhibit her knowledge that the object is really in location Y. Moreover, it has been shown that effortful control, and especially elements of attentional and inhibitory control, correlate highly with young children's ability to adapt to novel social situations (e.g. Caspi, 2000; Cumberland-Li, Eisenberg \& Reiser, 2004; Eisenberg, Fabes, Murphy, Maszk, Smith et al., 1995; Eisenberg et al., 1997; Eisenberg, Valiente, Fabes, Smith, Reiser et al., 2003a; Mischel \& Ayduk, 2004; Murphy, Shepard, Eisenberg \& Fabes, 2004).

In comparison to the broad literature on human selfregulation, very little is known about the self-regulatory abilities of our closest living relatives, the great apes, and hence the evolutionary roots of this important regulatory system which has been shown to have a huge impact on humans' cognitive and social development. In recent years, there have been several studies investigating individual differences in great ape temperament/ personality traits (Dutton, 2008; King \& Figueredo, 1997; King, Weiss \& Farmer, 2005; Massen et al., 2013; Uher et al., 2008; Weiss, King \& Figueredo, 2000). Similar personality dimensions to those found in humans, including conscientiousness, were revealed in chimpanzees, suggesting that individuals differ in their persistence, their delay of gratification and in their ability to 
control their impulses. However, these studies did not directly compare great apes with humans on these traits. Furthermore, there have been few experimental studies investigating inhibitory control in great apes (Amici, Aureli \& Call, 2008; Beran, Savage-Rumbaugh, Pate \& Rumbaugh, 1999; Evans \& Beran, 2007), and even fewer examining how great apes compare to humans (Rosati, Stevens, Hare \& Hauser, 2007; Vlamings, Hare \& Call, 2010). So far, these two studies suggest that great apes and young children have similar skills in an inhibitory detour-reaching task (Vlamings et al., 2010) and are even more willing to wait for a food reward than adults in a delay of gratification task (Rosati et al., 2007). However, apart from these few studies on inhibitory control and reactivity (Herrmann et al., 2011), there have been no human-ape comparative studies on other aspects of self-regulation, such as attentional control.

What is needed to gain a better understanding of the evolutionary roots of the human reactivity and selfregulatory system is a systematic comparison of a range of tasks trying to elicit spontaneous reactions and selfregulatory behaviors across different contexts among a single set of human children and humans' primate closest relatives. It has been shown that human selfregulation develops during ontogeny: e.g. inhibitory control skills in human children increase between 3 and 5 years of age (Kochanska et al., 2000; Kopp, 1989; Kopp \& Neufeld, 2003; Mischel \& Mischel, 1983; Murphy et al., 1999; Vlamings et al., 2010: Zelazo, Mueller, Frye \& Marcovitch, 2003). Therefore, in the current comparative study, we included two ages of children, one (3 years of age) before the reported increases in self-regulatory behavior, and the second (6 years of age) after regulatory skills are thought to increase. Using these two age groups allowed us to identify developmental stages in the chosen tasks and to compare nonhuman primates - specifically, one of humans' two closest relatives, chimpanzees (Pan troglodytes) - to the human ontogenetic trajectory.

We administered a battery of six tasks to 3 and 6-yearold children and chimpanzees. The battery consisted of two tasks in each of three categories, which together address the main components that researchers have investigated under the general heading of temperament: reactivity and self-regulation (inhibitory and attentional control). The first category, reactivity, had two tasks measuring subjects' approach-avoidance behavior in situations of novelty (shyness) and uncertainty (fearfulness). The second category, Inhibitory Control (a component of self-regulation), had two tasks, one requiring subjects to inhibit a prepotent response for immediate gratification (impulsiveness) and the other requiring inhibition of a prepotent response for a just-learned successful action when the situation was slightly changed (fixity). The third category, Attentional Control (again part of self-regulation), had two tasks requiring subjects to focus on a problem in spite of attractive distractions (focus) and repeated failures (persistence) (see Table 1).

Based on previous research (Kochanska et al., 2000; Lemmon \& Moore, 2007; Thompson, Barresi \& Moore, 1997; Eisenberg \& Morris, 2002; Kopp, 1989; Kopp \& Neufeld, 2003; Murphy et al., 1999), we expected that at 6 years of age, human children would have better inhibitory control and attentional control than at 3 years of age. Furthermore, previous research suggests that inhibitory control acts as an important constraint on chimpanzees in solving physical and social cognitive tasks (Boysen \& Berntson, 1995; Herrmann et al., 2007; Melis et al., 2006; see also Vlamings et al., 2010, for a species comparison). Thus, we predicted that human children would have better inhibitory control and would be less impulsive than their ape relatives. However, we had no clear prediction how chimpanzees would compare with human children in terms of their attentional control. Since previous research has shown that selfregulation develops during childhood, with an increase between 3 and 5 years of age, we predicted that 3-yearolds would behave more similarly to chimpanzees overall than the older children. In regard to their response to novelty and uncertainty, based on Herrmann et al. (2011), we predicted that human children would differ from chimpanzees in their approach-avoidance behavior, with chimpanzees being bolder or more interested in novel situations.

\section{Method}

\section{Participants}

Participants were 32 3-year-old children (16 girls; age range $=2,10-3,3)$ and 33 6-year-old children (17 girls; age range $=5,9-6,3$ ) from a medium sized German city. One 3-year-old child had to be partly excluded because of a technical error (Fearfulness), and five children had to be completely excluded due to being uncooperative. Five 6-year-old-children had to be partly excluded from the final analysis due to experimenter errors (Shyness, $n=1$; Fearfulness $n=1$; Persistence, $n=3$ ). Two additional 6-year-old children were tested but excluded due to experimenter errors, and one child due to being uncooperative. All participants were native German speakers. The children were tested in a child laboratory.

Furthermore, 34 chimpanzees (21 females; 7 to 25 years of age) participated in this study. Twenty chimpanzees had to be excluded from one task 
Table 1 Description of all six tasks

\begin{tabular}{|c|c|c|}
\hline Tasks & Description & Measure \\
\hline \multicolumn{3}{|l|}{ Reactivity } \\
\hline Shyness & $\begin{array}{l}\text { A novel object was placed in front of the subject and } \\
\text { her/his approach behavior was measured. }\end{array}$ & Latency to approach novel object. \\
\hline Fearfulness & $\begin{array}{l}\text { An opaque box containing a reward was presented to } \\
\text { the subject. Subjects had to overcome their } \\
\text { initial aversive feelings by reaching into this } \\
\text { dark and unpredictable box to obtain the reward }\end{array}$ & Latency to get the reward out of the box. \\
\hline Fixity & $\begin{array}{l}\text { Subjects had the experience of retrieving an out } \\
\text { of reach reward by using a rake. Suddenly the } \\
\text { situation changed and subjects had to inhibit } \\
\text { their predominant response and find a new } \\
\text { solution to the problem. }\end{array}$ & Number of trials until success. \\
\hline Persistence & $\begin{array}{l}\text { Subjects first experienced opening a box to retrieve } \\
\text { a reward. The box was then locked and subject's } \\
\text { persistence in trying to open the box in the face of } \\
\text { failure was examined. }\end{array}$ & $\begin{array}{l}\text { Percent of time subject manipulated } \\
\text { the box. }\end{array}$ \\
\hline
\end{tabular}

(impulsiveness) due to their dislike of using one of the relevant testing rooms. The chimpanzees lived at the Ngamba Island chimpanzee sanctuary, Lake Victoria, Uganda. All apes are orphans, were born in the wild and came to the sanctuary after being confiscated from the illegal bushmeat and pet trade. They were all raised by humans in a highly comparable way, living together with peers after arriving at the sanctuary. The chimpanzees (except two individuals) had access to a tropical forest (40 hectares) during the day. They were never food deprived for any reason and their diet (i.e. the food which was available in their enclosures) was supplemented two to four times daily with a combination of additional fruits, vegetables, and other species-appropriate foods.

\section{General materials}

Different rewards and slightly different materials were used across species to make sure that we addressed species-specific motivations. For most of the tasks, colorful dice were used as rewards and served as tokens for the children. Children were supposed to collect these in a 'Token Tower', which consisted of a $50 \mathrm{~cm}$ high transparent tube. Bananas and raisins were used as rewards for the apes. A cardboard or plastic occluder was used to prepare some tests outside the subject's view.

\section{General method}

Subjects participated in six tasks (see Table 1) and were individually tested by a female experimenter (E) in different rooms at the child lab (children) or in their holding facilities (chimpanzees). The human children were tested on one day and the apes on four days.

The six tasks were presented in the following fixed order:

\section{Shyness}

In this task a novel object was placed in front of the subject and her/his approach-avoidance behavior was measured. The basic method of this task was developed based on Herrmann et al. (2011).

\section{Children}

Novel object. To ensure the novelty of the presented toy, a colorful box $(32 \times 23 \times 22 \mathrm{~cm})$ with several small toys and noise-making objects attached (green hosepipe, a red flap making the sound of barking dogs when lifted, and colorful foam balls) was created and used.

Procedure. A novel object was placed $1.5 \mathrm{~m}$ away from a doorway at which $\mathrm{E}$ stopped and asked the child to 
wait a moment since she had forgotten something, turned away and left her standing alone at the door. The child was left alone for 30 seconds.

Coding and reliability. The subject's latency to approach the novel object was coded from video. Approach was coded when subjects entered a predetermined area $(65 \mathrm{~cm}$ away from starting point) after the start of the trial as a standardized measure of their approach behavior. Latency was measured as the interval between the starting time when the novel object was presented and the first time any part of the subject could be seen entering the predetermined space as they left their standardized starting point 1.5 meters away. In cases of no approach, subjects received a score of $30 \mathrm{~s}$ which resembles the entire trial length. For all tasks and each age and species, a second observer independently scored $20 \%$ of the trials. Inter-observer reliability was analyzed with Intraclass Correlation Coefficient (ICC). Inter-observer reliability was excellent (3-year-old children: $\mathrm{ICC}=.98 ; p<.001 ; 6$-year-old children: $\mathrm{ICC}=.99$; $p<.001)$.

\section{Chimpanzees}

Novel object. In comparison to the children, a more robust toy but with the same relevant features (colorful and noise-making) was used. A yellow plastic toy caterpillar with several buttons on its side was used. Pressing the buttons activated a variety of songs.

Procedure. At the beginning of the trial a caregiver called the subject's name and used small food pieces to attract the subject to a set starting position that was $\sim 1.5$ meters away from the a testing table, which was placed in front of the subject's room. Once the subject received a small food piece and was positioned, the trial started and the caregiver moved out of sight. A novel object was placed on the table within reach of the subject. The ape's behavior was assessed during the following 30 seconds.

Coding and reliability. The coding was identical to the children. Inter-observer reliability was excellent (ICC = $.87 ; p=.002)$.

\section{Fixity}

This task measured the subject's flexibility in their response behavior towards an unexpectedly changing situation. To be successful subjects had to inhibit a predominant response and had to find a new solution to a problem. The problem was either to avoid a trap in a table (3-year-old children/ chimpanzees) or in a tube (6-year-old children) to receive a reward. The task was developed based on Visalberghi and Limongelli (1994) and Povinelli (2000).

\section{Children}

Apparatus. Three-year-old children: A platform approximately $60 \times 80 \mathrm{~cm}$ was used, separated from the child by a Plexiglas window $(80 \mathrm{~cm} \times 40 \mathrm{~cm})$ with one hole (12 cm in diameter). On the child's side of the hole, a little tunnel with a xylophone inside was installed. The upper layer of the platform could be removed, revealing a trap in the second layer. A stick with a wooden semicircular end served as rake.

Six-year-old children: Two transparent tubes (length: $48 \mathrm{~cm}$, diameter: $5 \mathrm{~cm}$ ) which were attached to two separate blue boxes were used. One of them served as the pretest tube and was not manipulated in any way. The other tube, the Trap Tube, had a gap in the middle of its bottom. This trap opened into the blue box. Thus, objects pulled through the Trap Tube would fall through the gap and disappear into the blue box. A stick with a wooden semi-circular end that was exactly one half of the tube's diameter served as a rake.

Procedure. Introduction of token system: The child and E sat down at a table, facing each other. E introduced the tokens and the Token Tower. E explained that she was supposed to collect tokens in the Tower, and that all of the tokens gathered during the next tasks could be traded in for presents at the end.

Pretest: To measure flexibility, the children first had to acquire a fixed response behavior to a given task. For this purpose, the pretest tube with a token and a rake lying in the middle of it was presented to the child, and they were asked to get the token out of the tube. To be successful, the child simply needed to pull the rake out of the tube on the right side. The trial was repeated twice and $\mathrm{E}$ prepared each trial behind an occluder to avoid the child gathering any information about alternative ways of arranging the rake and token within the tube.

Test: During the test phase, the trap tube was presented to the child. If the child performed the same response and pulled the rake from the right side, the token would fall through the hole located between the token and the side from which the child had access to the rake. In order to obtain the reward, the child had to first inhibit the predominant response of pulling the rake, turn the rake around and then lift it on the other side of the token. After having turned the rake's semi-circulart end back to the lower side, the child had to push the token out on the left side of the tube. E instructed the child with the same words as in the pretest and did not advise or help the child. After 
each unsuccessful trial, E expressed sadness that the token was lost. E then prepared the next trial behind the occluder and motivated the child to try again. The trials were repeated until the child was either successful or 20 trials had been conducted.

The procedure for the 3-year-olds was almost the same as for the 6-year-olds, but with a simpler apparatus. Three-year-old children had to pull the token through the hole in front of them and got one demo trial before the pretest. For the test, the upper layer was removed, revealing the trap underneath. The children's task then was to navigate the token with the rake around the hole.

Coding and reliability. Out of 20 possible trials, the number of the trial on which the subject succeeded in obtaining the token/food reward from the Trap Tube/ Trap Table was coded. In cases of no success the subject received a score of 21. Inter-observer reliability for 3and 6-year-old children was excellent $(\mathrm{ICC}=1$; $p<.001)$.

\section{Chimpanzees}

Apparatus. A grey plastic box $(35 \times 35 \times 15 \mathrm{~cm})$, which was open on one side, was used. The platform on top of the box could be removed and the platform underneath had an opening $(10 \times 8 \mathrm{~cm})$ in the middle. Thus, food pulled over this trap would fall through the opening and disappear into the grey box. A metal rake $(31 \times 15 \mathrm{~cm})$ was provided to get access to the food.

Procedure. Pretest: As for the 3-year-old human children, a trap table was used. For this purpose, a banana piece was placed out of reach of the subject and a rake was positioned on a grey plastic box. To be successful, the ape needed to pull the rake towards her and rake the banana within reach. Each trial lasted 30 seconds. In case an ape did not use the rake within this time, E1 prepared a new trial behind an occluder. The pretest was repeated until the ape succeeded on three consecutive trials. The maximum number of trials was 20 .

Test: During the test phase, the platform on top was removed and the trap table was presented to the ape. If the ape performed the same response and pulled the rake straight towards her, the banana piece would fall through the hole which was placed between the reward and the subject. In order to obtain the reward, the ape had to first inhibit the predominant response of pulling the rake straight towards herself. Instead, the ape had to rake the reward within reach by moving the rake together with the reward around the hole. After each unsuccessful trial, E prepared the next trial behind an occluder and motivated, if necessary, the ape to try again by calling her name. The trials were repeated until the ape was either successful or 20 trials had been conducted.

Coding and reliability. The coding was identical to the children. Inter-observer reliability was excellent (ICC $=$ $1 ; p<.001)$.

\section{Fearfulness}

Subjects had to reach into a dark and unpredictable box which was filled with unfamiliar materials to obtain a reward.

\section{Children}

Materials. Two similar looking boxes $(42 \times 26 \mathrm{~cm})$ were located on small tables in two corners of the room. Each of them had a transparent attachment on top in which a token was visible. This token could only be obtained by reaching through an opening on the front side of the box. The clear box was transparent and empty inside. The scary box was stuffed with unfamiliar and rather strange materials like foamed plastic, styrofoam, and slimy material which was attached to the inner walls of the box. Dark cloth pieces behind the opening of the hole prevented the children from seeing the contents.

Procedure. Pretest: After E and the child sat down at the table, E pointed out one token in the clear box in the corner of the room. She explained that the child could get the token by reaching into the box through the front opening, meaning that they had to insert their whole arm into the box. Children were asked to get the token.

Test: After the child successfully obtained the token from the clear box, E pointed out that there was another token in a second box (Scary Box). The child was told that they could also get the token out of that box, while E herself would prepare the next game. Then E disappeared behind a screen and pretended to be busy. The child had 2 minutes to overcome their inhibitions and reach into the box despite the unpleasant materials inside. If the child did not dare to insert their hand into the box, E motivated them after 1 minute, mentioning that the child was allowed to put the token from the box into the Token Tower.

Coding and reliability. First the latency to get the food/ token out of the box was coded for both the pretest and the test. The starting point for both the pretest and the test was set at the moment the subject was within reach of the respective box. The end point was defined as when the food/token was visible outside the box. Then, a difference score between latency to get the reward in the test and 
latency to get the reward in the pretest was calculated. Using the pretest score as a baseline excluded the possibility of simply capturing the subject's general slowness instead of their fearfulness. In cases where subjects did not reach into the box and obtain the reward, a score of 120 seconds was assigned. Inter-observer reliability for 3-year-old children (ICC $=.99 ; p<.001$ ) and 6 -year-old children (ICC $=1 ; p<.001$ ) was excellent.

\section{Chimpanzees}

Materials. An L-shaped black Plexiglas box $(30 \times 17 \times 20 \mathrm{~cm}$, with a clear extension on the far end side $7 \times 10 \times 20 \mathrm{~cm}$ ) was attached to a testing table and to the bars from outside the subject's room. The box had an opening $(15 \times 15.5 \mathrm{~cm})$ on the front, facing the subject which allowed the chimpanzee to reach into the box. For the pretest phase the box was empty inside. For the test phase the box was stuffed with different plastic material covering the wall, wool and other furry material hanging from the top. The materials in the test box differed between chimpanzees and human children to make sure to address species-specific dislikes. A burlap piece at the opening of the hole prevented the apes from seeing the contents.

Procedure. Pretest: An empty box was attached to the bars outside the subject's room. The experimenter placed half a banana in the clear part at the far end of the box in full view of the subject while calling the subject's name. Then the subject was allowed access to the box. The pretests ended when the ape had reached into the box and obtained the food.

Test: On the following day, the same box but now containing several different materials was attached to the bars outside the subject's room. As in the pretest, the experimenter placed half a banana in the clear part at the far end of the box in full view of the subject while calling the subject's name. Then the subject was allowed access to the box. The trial started when the subject was within reach of the box, and lasted 2 minutes. In cases where the subject hadn't reached into the box after 1 minute, an additional food piece was placed in the clear part of the box.

Coding and reliability. The coding was identical to that for the children. Inter-observer reliability $(\mathrm{ICC}=.99$; $p<.001)$ was excellent.

\section{Persistence}

In this task subject's persistence in trying to obtain a reward that was suddenly impossible to get was examined.
A similar method was used with nonhuman apes in Uher et al. (2008).

\section{Children}

Materials. A transparent container was attached to the top of a wooden box $(12 \times 12 \times 8 \mathrm{~cm})$. The container was only attached with a hinge on one side and could be lifted easily on the other side with a handle. The handle could be locked such that the opening of the container was blocked by pressing a button on the back side of the box not visible to the children.

Procedure. Introduction: The child and E sat at the table. E showed the child how the persistence box which contained a token could be opened by lifting the container with the handle. Subsequently, the child was asked to get the token out of the box and put it into the Token Tower.

Test: E prepared the box behind an occluder. After a token was placed inside the box, E locked it so that the subject could no longer open it. E then placed the locked box in front of the subject and turned away. After 2 minutes the trial ended.

Coding and reliability. The percent of time the subject manipulated the box was coded. A break was coded if the subject did not touch the box for at least 2 seconds. Inter-observer reliability for 3-year-old children (ICC $=$ $.99 ; p<.001)$ and 6-year-old children (ICC $=.96$; $p<.001)$ was excellent.

\section{Chimpanzees}

Materials. A transparent container $(12 \times 12 \times 8 \mathrm{~cm})$, identical to the one used for human children, was attached to the top of a wooden board $(27 \times 20 \mathrm{~cm})$. The container was only attached with a hinge on one side and could be lifted easily on the other side with a handle. The handle could be locked, such that the opening of the container was blocked, by placing a screw through the handle which went through the wooden board and was fixed with a nut. This blocking mechanism was not visible to the apes.

Procedure. Introduction: E called the ape's name and demonstrated how the persistence box which contained a piece of banana could be opened by lifting the container with the handle. E repeated this demonstration three times. Subsequently, the ape was allowed to get the banana by E pushing the box against the mesh and within reach. The introduction ended after the ape successfully opened the box three times. 
Test: E prepared the box behind an occluder. After a banana piece was placed inside the box, E locked it so that the subject could no longer open it. E then placed the locked box within reach of the subject and turned away. After 2 minutes the trial ended.

Coding and reliability. Coding was identical to the children. Inter-observer (ICC $=.98 ; p<.001$ ) was excellent.

\section{Focus}

This task investigated how well subjects could focus on a task despite a distractive unexpected and unknown noise. A similar method was used with nonhuman apes in Uher et al. (2008). The task differed between species to ensure that each species was interested and engaged in the given task at the time the distractive noise occurred.

\section{Children}

Materials. A jigsaw-like puzzle game with 12 missing pieces $(3 \times 3 \mathrm{~cm})$ was developed for this task. The missing pieces could be pulled out of a dispenser one by one by pulling open a little drawer. As distraction noise a 10 second sequence of six different and novel computergenerated synthetic noises were used.

Procedure. Introduction: The children were presented with a jigsaw puzzle game. E pointed out the empty spaces in the picture and demonstrated how the child had to pull the little drawer of a dispenser in order to get one of the missing pieces for the jigsaw. E placed the first piece in the correct position together with the child. E explained that it was the child's task to pull each piece, one after the other, out of the dispenser and find the right position in the jigsaw for it. Before $\mathrm{E}$ left the room, she promised the child more tokens if the jigsaw was finished upon her return.

Test: Just before leaving the room, E secretly used a remote control to switch on the distraction noise from a hidden iPod. After 30 seconds of silence the noise was played from the hidden speakers. The noise lasted 10 seconds. Following this, a second period of $30 \mathrm{sec}-$ onds of silence took place before the same sound played for another 10 seconds. The test ended after a third 30 second period of silence.

Coding and reliability. The percent of time the child focused on the puzzle within the first 10 second noise period was used. The score was calculated as follows: 100 percent of the 10 second period minus the time the subject did not focus on the task, which was defined by the percent duration looking up (child looks up from the puzzle, either surprised or looking around and searching for the source of noise). Inter-observer reliability for 3and 6-year-old children (ICC $=.99 ; p<.001)$ was excellent.

\section{Chimpanzees}

Materials. A wooden block with several holes which contained raisins served as task. The wooden block was attached to the bars with a steel rope. As distraction noise a 10 second sequence of six different and novel computer-generated synthetic noises were used.

Procedure. Introduction: On a previous day the apes were presented with a wooden block with holes which were filled with raisins. The subjects were allowed to manipulate the wooden block for 2 minutes. This introduction was carried out to ensure that the apes liked raisins and were interested in manipulating the block for 2 minutes. All apes mastered the pretest and manipulated the wooden block.

Test: A wooden block filled with raisins was attached to the mesh and speakers were hidden outside the subject's room under a piece of cloth 3 meters away from the block. The trial started as soon as the subject entered the room and started manipulating the block. The noise manipulation was the same as for the children.

Coding and reliability. The percent of time the chimpanzee focused on the raisin block within the first 10 second noise period was used. The score was calculated as follows: $100 \%$ of the 10 second period minus the time the subject did not focus on the task, which was defined by the percent duration looking and/or moved towards the noise source. Inter-observer reliability was excellent $(\mathrm{ICC}=.98 ; p<.001)$.

\section{Impulsiveness}

This task measured the subject's willingness to exert greater effort for a larger reward. The task involved a choice between a nearby, smaller reward (one piece) versus a further away, larger reward (three pieces). The task was developed based on work on nonhuman primates by Stevens, Rosati, Ross and Hauser (2005).

\section{Children}

Materials. On a $4.9 \times 3.6$ meter white carpet, three trails, two short ones $(2 \mathrm{~m})$ and, between the two, one long one $(16 \mathrm{~m})$, were marked with black adhesive tape (6-year-olds) or painted with green colour (3-year-olds). 
Foam material was attached as a barrier between the trails on the carpet for the 3-year-olds. A colored circle marked the starting point of all three trails.

Procedure. Introduction: E1 explained the game to the child by pointing out that the lines on the carpet marked trails and that walking was only permitted on those trails, and not on the white parts of the carpet. To emphasize this rule, E1 and the child took off their shoes before stepping on the carpet. E1 and the child then explored the trail system by walking along each single trail.

Pretest: A pretest was conducted to ensure that the child had an understanding of different amounts (three versus one) and also valued three tokens more than one (for more details see Supporting Information).

Test: Each test trial started with a second experimenter (E2) placing one token at the end of the short right-hand side path and three tokens at the end of the long path. The child, standing on the green starting point, was asked to choose one path. E1 pointed out both trails' ends with the tokens and made sure that the subject had seen both of them. The child was then allowed to go along the path they chose and take the tokens. A trial ended with the child's return to the starting point and the next trial started immediately after. The test phase consisted of four trials.

Coding and reliability. The number of choices for the short way and hence for the smaller amount was counted. Inter-observer reliability for 3- and 6-year-old children was excellent $(\mathrm{ICC}=1 ; p<.001)$.

\section{Chimpanzees}

Materials. Instead of the carpet with trails used by the humans, different rooms of the apes' holding/testing facilities were used. This difference in method was chosen to ensure that the apes were able to understand the procedure of the study without verbal instruction.

Procedure. Introduction: During the introduction the subject was supposed to learn that they were only allowed to make one choice out of two possibilities. The subject observed E placing the same amount of food (one banana piece) in two separate rooms equidistant from the subject's starting room while getting the subject's attention by calling her name. After the baiting the two doors to the adjacent rooms were opened simultaneously and the subject was allowed to make one choice. After the subject entered one of the baited rooms, the door of the room the subject was in was closed. The subject received four introduction trials. The order of the baiting of both rooms was counterbalanced across trials.
Pretest 1: Pretest 1 was conducted to make sure that the ape had an understanding of different amounts (three versus one) and also valued three pieces of food more than one (for more details see Supporting Information).

Pretest 2: Pretest 2 was conducted to make sure that the ape had an understanding of the interconnecting rooms and their doors which could be either open or closed (for more details see Supporting Information).

Test: Immediately before the test trials, two pretest 2 trials were conducted to remind the subject about the test setup. Each test trial started with E placing one piece of food in an adjacent room and three pieces of food in a room which was further away and was separated by two additional rooms. E tried to get the subject's attention by calling her name while baiting. After the baiting the two doors to the adjacent rooms were opened simultaneously and the subject was allowed to make one choice. After the subject entered one adjacent room, the door of the room the subject was in was closed. The test phase consisted of four trials. The order of the baiting of both rooms and the amount of food in each room was counterbalanced across trials.

Coding and reliability. Coding was identical to the children. Inter-observer reliability was excellent $(\mathrm{ICC}=$ $1 ; p<.001)$.

\section{Data analyses}

Two variables of the study included censored observations. This is the case for Shyness (subject that did not approach the novel object at the end of the observation) and for Fixity (subject that did not succeed in the task). Applying standard statistical methods to censored data, or not taking them into account, can lead to biased estimates. The survival analysis approach deals with this problem neatly (Budaev, 1997). Survival analysis offers powerful techniques to compare the survival functions (i.e. the proportion of individuals not experiencing the event, or the probability that the event will not occur until time t) of different samples. Hence we applied Kaplan-Meier survival analysis (Kaplan \& Meier, 1958), a nonparametric survival analysis, to relate latency to approach and number of trials to succeed (for Shyness and Fixity, respectively) to the species. Comparisons between the three grouped survival curves (for chimpanzees, 3- and 6-year-old children) were performed using a permutation based log rank test. Pair-wise post-hoc analyses were performed with the same technique using a Bonferroni adjustment for multiple comparisons. Noncensored latencies, Fearfulness scores (that were log transformed to produce normality) and continuous variables (Persistence and Focus) across species were 
compared via one-way independent measures ANOVAs. Post-hoc tests (Scheffe correction when equality of variances assumption holds, and Games-Howell otherwise) followed if a significant effect was detected. In addition, for variables with important deviations of the model assumptions, we tested for differences using a Kruskal-Wallis one-way ANOVA by ranks. Mann-Whitney $\mathrm{U}$ tests were used as post-hoc tests (using Bonferroni correction). Transforms to produce normality were evaluated where appropriate. All statistical analyses were performed in SPSS 19.

\section{Results and discussion}

\section{Shyness and fearfulness}

On the two tasks of Reactivity, the pattern of results was the same (see Figures 1a, 1b and Figure S1 for a full distribution of responses for each group).

The three groups differed in their response towards a novel object (Log Rank Mantel-Cox test, chi-square = 7.672; $d f=2, p<.022)$ and in fearfulness $\left(F_{2,90}=3.127\right.$, $p=.049 ; \eta^{2}=0.06$ ). Post-hoc multiple comparisons revealed that chimpanzees were quicker/ less shy to approach a novel object than were the 6-year-old children $(p<.001)$. In addition, post-hoc tests (Games-Howell correction) in the fearfulness task revealed that chimpanzees were quicker/ less fearful to reach into a 'scary box' than were the 6-year-old children $(p=.008)$. The 3-yearold children were in between, not statistically different from either of the other two groups. These results are generally compatible with those of Herrmann et al. (2011), who found that great apes in general approached novel objects and people more quickly than did human children. The lack of a significant age difference in children is compatible with proposals that this more reactive and involuntary dimension of human temperament is not something that changes greatly in human ontogeny (Kagan \& Snidman, 2004; Rothbart \& Derryberry, 1981).

\section{Fixity and impulsiveness}

On the two tasks of Inhibitory Control, the clearest differences were again between the chimpanzees and the 6-year-old children (see Figures 1c,1d, and S2 for a full distribution of responses for each group).

The three groups differed in their inhibitory control skills (Impulsiveness: Kruskal-Wallis one-way ANOVA: $\left.\chi_{3}^{2}=10.671, p=.005\right)$ and (Fixity: Log Rank Mantel-Cox test; chi-square $=39.916 ; d f=2, p<.001)$. Post-hoc tests revealed that the 6-year-old children were able to inhibit a prepotent response (to go for a small reward close by) in order to gain greater rewards (going for a larger reward farther away) much better than were the chimpanzees (Mann-Whitney U tests: $p=.003$ ). The 3-year-olds were not statistically different from either of these two groups, but were numerically in between. The 6-year-old children were also better able to adapt their behavioral strategy to a changed situation - by inhibiting a response that had been previously successful in a similar situation - than were the chimpanzees $(p<.001)$. In this case, the 3 -year-old children patterned with the chimpanzees and their behavior differed significantly from the older children $(p<.001)$. This age difference is consistent with previous research showing that inhibitory control skills in human children increase between 3 and 5 years of age (Kochanska et al., 2000; Kopp, 1989; Kopp \& Neufeld, 2003; Mischel \& Mischel, 1983; Murphy et al., 1999; Vlamings et al., 2010: Zelazo et al., 2003). In contrast to previous research showing that 3-year-olds tend to take immediate rewards whereas older children more often delay (Mischel \& Mischel, 1983; Lemmon \& Moore, 2007) (see also for a comparison with apes, Rosati et al., 2007), we did not find this age difference. This difference could be a result of the different methods which were used. Instead of waiting for a longer reward, subjects had to walk for a longer distance in order to retrieve a larger reward. The finding that chimpanzees and 3-year-old children were less skillful in inhibiting a prepotent response supports the idea that inhibitory control may act as an important constraint on chimpanzees and possibly on younger children in solving physical and social cognitive tasks (Boysen \& Berntson, 1995; Herrmann et al., 2007; Melis et al., 2006).

\section{Focus and persistence}

On the two tasks of Attentional Control, once more the greatest difference was between the 6-year-old children and the chimpanzees (see Figures 1e and if for a full distribution of responses for each group).

Performance in attentional control skills differed significantly across groups (Focus: $F_{2,}, 96=5.215$, $p<.007, \eta 2=0.10$ ) and (Persistence: $F_{2,93}=6.022$, $p=.003, \eta^{2}=0.12$ ). Post-hoc tests (Scheffe correction) revealed that the 6-year-old children were better able than the chimpanzees to stay focused on a task in spite of distracting noises $(p=.011)$. The 3-year-old children were again not statistically different from either group, but numerically in between. Furthermore, post-hoc tests (Games-Howell correction) revealed that 6-year-old children were also better able than the chimpanzees to persist in trying to solve a difficult task in spite of failure $(p=.002)$. In this case, the 3-year-old children showed the lower level of persistence characteristic of chimpanzees and differed significantly from the older children 

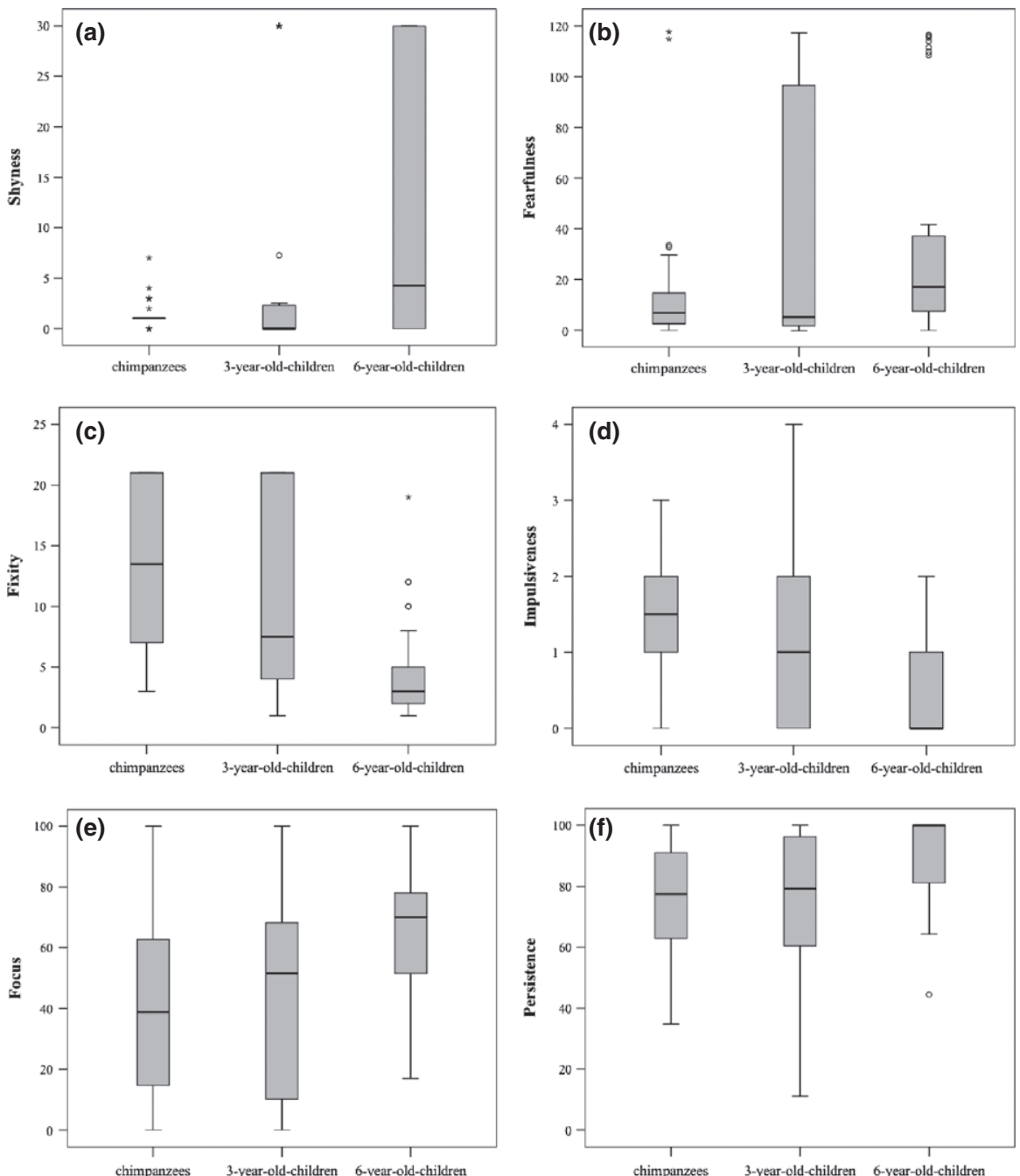

Figure 1 a-f The box plots show the full distribution of responses on the six tasks for each group: median, quartiles, and extreme values. In all six tasks chimpanzee behaved significantly differently from 6-year-old children but not 3-year-olds. Three-year-old children differed significantly from 6-year-old children in the fixity (1c) and focus (1e) tasks. The respective y-axis represents the latency to approach a novel object (1a); latency to get the reward out of the box (1b); number of trials until success (1c). (1d) number of choices for the smaller and immediate reward; (1e) percent of time subject focused on the puzzle/raisin block during the noise period; (1f) percent of time subject manipulated the box. Boxes represent the interquartile range that contains $50 \%$ of values (range from the 25th to the 75th percentile). The line across the box indicates the median. The whiskers represent maximum and minimum values, excluding outliers [indicated by circles, at least 1.5 times the interquartile range (i.e. 1.5 box lengths from the upper or lower edge of the box)] and extremes [indicated by asterisks, at least 3 times the interquartile range (i.e. $>3$ box lengths from the edge)].

$(p=.010)$. In general, previous research with children on attentional focusing has investigated school-age children and has found mixed results ranging from no large developmental changes (Zhou, Hofer, Eisenberg, Reiser, Spinrad et al., 2007) to clear developmental changes (Rebok, Smith, Pascualvaca, Mirsky, Anthony et al., 1997; Klenberg, Korkman \& Lahti-Nuuttila, 2001). It is difficult to compare this study with previous ones, since both the methods (questionnaires vs. behavioral assessments) and tasks vary. Previous studies of behavioral persistence have found mixed results. However, an increase in persistence was detected when they included a larger age range (Eisenberg, Spinrad, Fabes, Reiser, Cumberland et al., 2004; Zhou et al., 2007).

\section{General discussion}

The current study showed that 3- and 6-year-old human children's and chimpanzees' reactivity and self-regulation 
differed in important ways. Human children showed a stronger aversive response to novel or mildly frightening objects than did chimpanzees. But in situations where subjects had to modulate/regulate their reactivity, the 6year-old children were better able to control and manage their impulses than chimpanzees. The 6-year-olds were better at resisting the impulse for immediate gratification (when doing so led to greater reward later); they were better at resisting the impulse to repeat a previously successful action (when the problem situation had changed slightly); they were better at resisting the impulse to attend to loud, distracting noises (when this would have impaired their problem-solving); and they were better at resisting the temptation to quit in the face of repeated failure.

Interestingly, the 3-year-old children in the current study were not significantly more skillful at managing their impulses than were the chimpanzees on any of these tasks, which suggests that children's most fundamental skills of self-regulation have deep evolutionary roots. The progress in self-control on some tasks exhibited in children from age 3 to age 6 in the current study is consistent with most developmental research. For instance, there are a number of correlational findings suggesting that parental behavior helps to shape individual children's skills (Eisenberg, Zhou, Losoya, Fabes, Shepard et al., 2003b; Kochanska et al., 2000). In addition, parents also adjust their strategies to influence their children's behavior as children grow older and their competence increases (Lamb \& Lewis, 2005). This kind of teaching is present in one form or another in all human societies (Kruger \& Tomasello 1996), but it is clearly not an everyday occurrence in chimpanzees (but see e.g. two single observations of Boesch, 1991). Ape parents do not actively teach their children or actively attempt to shape their child's behavior in the same ways that humans do.

The developmental change in self-regulatory skills is also consistent with the general observation that in various cultures (despite cultural variations in the exact ages) in which there is some type of formal education or some assignment to children of culturally important tasks - children are expected to have achieved various competencies around middle childhood (Goodnow, Cashmore, Cotton \& Knight, 1984; Lamb \& Lewis, 2005; Lightfoot, Cole \& Cole, 2013). Almost certainly, children's newly developing and species-unique skills of behavioral and attentional self-control are subject to this judgment and are fundamental to fulfilling adult expectations.

Our findings thus suggest that the influence of adults on children's temperament most likely occurs or starts to have an impact only from age 3 onward. At age 3, young children still seem to have very similar self-regulation skills as nonhuman apes. By the age of 6 years, children begin to show the kinds of unique skills that humans use to control themselves especially effectively in the face of all kinds of temptations and distractions. In general, many studies with young children have shown that individual differences in self-regulation have a huge impact on children's cognitive, emotional and social development (Posner \& Rothbart, 2000) and seem to predict health, wealth and criminal trajectories (Moffitt, Arseneault, Belsky, Dickson, Hancox et al., 2011). Socially, effortful control correlates highly with young children's ability to adapt to novel social situations, including those in which they must behave according to adult rules (e.g. the school classroom) as well as those in which they must interact positively with novel peers, possibly because cooperating with peers often requires inhibiting one's initial impulses for such things as grabbing desired objects, taking the first turn, and so forth (e.g. Caspi, 2000; Cumberland-Li et al., 2004; Eisenberg et al., 1995, 1997, 2003a; Mischel \& Ayduk, 2004; Murphy et al., 2004). The lack of refined selfregulatory skills, which can be seen in adults, could act as an important constraint on chimpanzees and possibly on younger children in solving physical and social cognitive tasks (Boysen \& Berntson, 1995; Herrmann et al., 2007; Melis et al., 2006).

This is the first study to systematically compare human children and chimpanzees on a comprehensive test battery comprising both dimensions of temperament: reactivity and self-regulation. As such, it provides an important first step in documenting some of the evolutionary roots of human skills of self-regulation, but it also has important limitations since comparisons of different species always pose certain challenges. The greatest challenge of such studies is to achieve maximum comparability between human and ape versions of a given task. Maximum comparability doesn't necessitate using exactly the same materials and methods, but does require that one take into account species-specific motivations for the given task. In the current study, we tried to be sensitive to species differences when choosing our tasks and adapted them for each species in an effort to ensure applicability and relevance. Even when using a slightly different setup in one of the two inhibitory and attentional control tasks (impulsiveness and focus), the same results were found as in the tasks in which the apparatuses were the same across species (fixity and persistence). In addition, the six tasks were chosen for optimal ecological validity respective to both species. The ability to regulate impulses is not only advantageous for human children (Posner \& Rothbart, 2000) but also for chimpanzees. Inhibitory and attentional control are 
especially important in the context of foraging, for example when chimpanzees make decisions on where to forage (choosing between small patches of food close by or risking searching for larger patches further away), when they engage in foraging methods requiring focused effort (extractive foraging), and when they ignore urges to reach for food in another's possession or when a more dominant individual is near.

Future research should focus on even more diverse tasks and contexts, especially the field of attentional control (since this was the first comparative attempt) involving skills such as shifting attention and making decisions in the presence of conflicting stimuli. In general, using a broader age spectrum and other nonhuman ape species could help us to determine whether the differences we see in regulatory abilities are qualitative or just quantitative in nature.

\section{Acknowledgements}

We are grateful to the management, in particular Lilly Ajarova, the animal caregivers, and the trustees of Ngamba Island Chimpanzee Sanctuary for their enthusiasm, help, and support. We also thank the Ugandan National Council for Science and Technology and the Uganda Wildlife Authority for their support of our research. In particular we appreciate the hard work of the animal caregivers: Stany Nyandwi, Mandy Musumba, Gerald Muyingo, Phillip Sekulya, Paul Nyenje, Bruce Ainebyona, Innocent Ampeire, Rodney Anabo and Byron Ssemambo. Special thanks go to Manja Teich, Angela Loose, Irka Wetzig, Elvira Plötner and AnnaClaire Schneider for their enormous help with organization and data collection. We also thank the parents and children who participated in this study.

\section{References}

Amici, F., Aureli, F., \& Call, J. (2008). Fission-fusion dynamics, behavioral flexibility and inhibitory control in primates. Current Biology, 18, 1415-1419.

Baumeister, R.F., \& Heatherton, T.F. (1996). Self-regulation failure: an overview. Psychological Inquiry, 7, 1-15.

Beran, M.J., Savage-Rumbaugh, E.S., Pate, J.L., \& Rumbaugh, D.M. (1999). Delay of gratification in chimpanzees (Pan troglodytes). Developmental Psychobiology, 34, 119-127.

Boesch, C. (1991). Teaching among wild chimpanzees. Animal Behaviour, 41, 530-532.

Boysen, S.T., \& Berntson, G.G. (1995). Responses to quantity: perceptual versus cognitive mechanisms chimpanzees (Pan troglodytes). Journal of Experimental Psychology: Animal Behavior Processes, 21 (1), 82-86.
Budaev, S.V. (1997). The statistical analysis of behavioural latency measures. ISCP Newsletter, 14 (1), 1-4.

Carlson, S.M., \& Moses, L.J. (2001). Individual differences in inhibitory control and children's theory of mind. Child Development, 72, 1032-1053.

Carlson, S.M., Moses, L.J., \& Claxton, L.J. (2004). Individual differences in executive functioning and theory of mind: an investigation of inhibitory control and planning ability. Journal of Experimental Child Psychology, 87 (4), 299-319.

Caspi, A. (2000). The child is father of the man: personality continuities from childhood to adulthood. Journal of Personality and Social Psychology, 78 (1), 158-172.

Cumberland-Li, A., Eisenberg, N., \& Reiser, M. (2004). Relations of young children's agreeableness and resiliency to effortful control and impulsivity. Social Development, 13 (2), 193-212.

Diamond, A. (2013). Executive functions. Annual Review of Psychology, 64, 135-168.

Dutton, D.M. (2008). Subjective assessment of chimpanzee (Pan troglodytes) personality: reliability and stability of trait ratings. Primates, 49, 253-259.

Eisenberg, N., Fabes, R.A., Murphy, B., Maszk, P., Smith, M. et al. (1995). The role of emotionality and regulation in children's social functioning: a longitudinal study. Child Development, 66 (5), 1360-1384.

Eisenberg, N., Guthrie, I.K., Fabes, R.A., Reiser, M., Murphy, B.C. et al. (1997). The relations of regulation and emotionality to resiliency and competent social functioning in elementary school children. Child Development, 68 (2), 295-311.

Eisenberg, N., \& Morris, A.S. (2002). Children's emotionrelated regulation. In R.V. Kail (Ed.), Advances in child development and behavior, Vol. 30 (pp. 189-229). San Diego, CA: Academic Press.

Eisenberg, N., Spinrad, T., Fabes, R., Reiser, M., Cumberland, A. et al. (2004). The relations of effortful control and impulsivity to children's resiliency and adjustment. Child Development, 75 (1), 25-46.

Eisenberg, N., Valiente, C., Fabes, R.A., Smith, C.L., Reiser, M. et al. (2003a). The relations of effortful control and ego control to children's resiliency and social functioning. Developmental Psychology, 39, 761-776.

Eisenberg, N., Zhou, Q., Losoya, S.H., Fabes, R.A., Shepard, S.A. et al. (2003b). The relations of parenting, effortful control, and ego control to children's emotional expressivity. Child Development, 74 (3), 875-895.

Evans, T.A., \& Beran, M.J. (2007). Chimpanzees use selfdistraction to cope with impulsivity. Biology Letters, 3, 599602.

Freeman, H.D., \& Gosling, S.D. (2010). Personality in nonhuman primates: a review and evaluation of past research. American Journal of Primatology, 72, 653-671.

Glickman, S.E., \& Sroges, R.W. (1966). Curiosity in zoo animals. Behaviour, 26, 151-188.

Goodnow, J.J., Cashmore, J., Cotton, S., \& Knight, R. (1984). Mothers' developmental timetables in two cultural groups. International Journal of Psychology, 19, 193-205. 
Gosling, S.D. (2001). From mice to men: what can we learn about personality from animal research? Psychological Bulletin, 127, 45-86.

Hala, S., Hug, S., \& Henderson, A. (2003). Executive function and false-belief understanding in preschool children: two tasks are harder than one. Journal of Cognition and Development, 4, 275-298.

Hare, B. (2007). From nonhuman to human mind: what changed and why. Current Directions in Psychological Science, 16, 60-64.

Hare, B., Melis, A., Woods, V., Hastings, S., \& Wrangham, R. (2007). Tolerance allows bonobos to outperform chimpanzees in a cooperative task. Current Biology, 17, 619-623.

Hare, B., \& Tomasello, M. (2005). The emotional reactivity hypothesis and cognitive evolution. Trends in Cognitive Sciences, 10, 464-465.

Hebb, D.O. (1949). Temperament in chimpanzees: I. Method and analyses. Journal of Comparative and Physiological Psychology, 42, 192-206.

Herrmann, E., Call, J., Hernández-Lloreda, M.V., Hare, B., \& Tomasello, M. (2007). Humans have evolved specialized skills of social cognition: the cultural intelligence hypothesis. Science, 317, 1360-1366.

Herrmann, E., Hare, B., Cissewski, J., \& Tomasello, M. (2011). A comparison of temperament in nonhuman apes and human infants. Developmental Science, 14, 1393-1405.

Jackson, J.J., Bogg, T., Walton, K., Wood, D., Harms, P.D. et al. (2009). Not all conscientiousness scales change alike: a multi-method, multi-sample study of age differences in the facets of conscientiousness. Journal of Personality and Social Psychology, 96, 446-459.

Kagan, J. (1997). Temperament and the reactions to unfamiliarity. Child Development, 68, 139-143.

Kagan, J., \& Snidman, N. (2004). The long shadow of temperament. Cambridge, MA: Belknap Press of Harvard University Press.

Kaplan, E.L., \& Meier, P. (1958). Nonparametric estimation from incomplete observations. Journal of the American Statistical Association, 53, 457-485.

King, J.E., \& Figueredo, A.J. (1997). The Five-Factor Model plus dominance in chimpanzee personality. Journal of Research in Personality, 31, 257-271.

King, J.E., Weiss, A., \& Farmer, K.H. (2005). A chimpanzee (Pan troglodytes) analogue of crossnational generalization of personality structure: zoological parks and an African sanctuary. Journal of Personality, 73, 389-410.

Klenberg, L., Korkman, M., \& Lahti-Nuuttila, P. (2001). A differential development of attention and executive functions in 3- to 12-year-old Finnish children. Developmental Neuropsychology, 20 (1), 407-428.

Kochanska, G., Murray, K., \& Coy, K.C. (1997). Inhibitory control as a contributor to conscience in childhood: from toddler to early school age. Child Development, 68 (2), 263 277.

Kochanska, G., Murray, K.T., \& Harlan, E.T. (2000). Effortful control in early childhood: continuity and change, anteced- ents, and implications for social development. Developmental Psychology, 36 (2), 220-232.

Kochanska, G., Murray, K., Jacques, T.Y., Koenig, A.L., \& Vandegeest, K.A. (1996). Inhibitory control in young children and its role in emerging internalization. Child Development, 67 (2), 490-507.

Kopp, C.B. (1989). Regulation of distress and negative emotions: a developmental view. Developmental Psychology, 25 (3), 343-354.

Kopp, C.B., \& Neufeld, S.J. (2003). Emotional development during infancy. In R. Davidson, K.R. Scherer \& H.H. Goldsmith (Eds.), Handbook of affective sciences (pp. 347374). Oxford: Oxford University Press.

Kruger, A., \& Tomasello, M. (1996). Cultural learning and learning culture. In D. Olson (Ed.), Handbook of education and human development: New models of teaching, learning, and schooling (pp. 369-387). Malden, MA: Blackwell.

Lamb, M.E., \& Lewis, C. (2005). The role of parent-child relationships in child development. In M.H. Bornstein \& M.E. Lamb (Eds.), Developmental science: An advanced textbook (5th edn.) (pp. 429-468). Mahwah, NJ: Lawrence Erlbaum Associates.

Lemmon, K., \& Moore, C. (2007). The development of prudence in the face of varying future rewards. Developmental Science, 10, 502-511.

Lightfoot, C., Cole, M., \& Cole, S.R. (2013). The development of children. New York: Worth Publishers.

Lilienfeld, S.O., Gershon, J., Duke, M., Marino, L., \& de Waal, F.B.M. (1999). A preliminary investigation of the construct of psychopathic personality (psychopathy) in chimpanzees (Pan troglodytes). Journal of Comparative Psychology, 113, 365-375.

Massen, J.J.M., Antonides, A., Arnold, A., Bionda, T., \& Koski, S.E. (2013). A behavioral view on chimpanzee personality: exploration tendency, persistence, boldness, and tool-orientation measured with group experiments. American Journal of Primatology, 75, 947-958.

Melis, A.P., Hare, B., \& Tomasello, M. (2006). Chimpanzees recruit the best collaborators. Science, 311, 1297-1300.

Mischel, H.N., \& Mischel, W. (1983). The development of children's knowledge of self-control strategies. Child Development, 54, 603-619.

Mischel, W., \& Ayduk, O. (2004). Willpower in a cognitiveaffective processing system: the dynamics of delay of gratification. In R.F. Baumeister \& K.D. Vohs (Eds.), Handbook of self-regulation (pp. 99-129). New York: Guilford Press.

Moffitt, T.E., Arseneault, L., Belsky, D., Dickson, N., Hancox, R. et al. (2011). A gradient of childhood self-control predicts health, wealth, and public safety. Proceedings of the National Academy of Sciences, USA, 108, 2693-2698.

Murphy, B.C., Eisenberg, N., Fabes, R.A., Shepard, S., \& Guthrie, I.K. (1999). Consistency and change in children's emotionality and regulation: a longitudinal study. MerrillPalmer Quarterly: Journal of Developmental Psychology, 45 (3), 413-444.

Murphy, B.C., Shepard, S.A., Eisenberg, N., \& Fabes, R.A. (2004). Concurrent and across time prediction of young 
adolescents' social functioning: the role of emotionality and regulation. Social Development, 13 (1), 56-86.

Parker, C.E. (1974). Behavioral diversity in ten species of nonhuman primates. Journal of Comparative and Physiological Psychology, 87, 930-937.

Perner, J., Lang, B., \& Kloo, D. (2002). Theory of mind and self-control: more than a common problem of inhibition. Child Development, 73, 752-767.

Posner, M.I., \& Rothbart, M.K. (2000). Developing mechanisms of self-regulation. Development and Psychopathology, 12 (3), 427-441.

Povinelli, D. (2000). Folk physics for apes: The chimpanzee's theory of how the world works. Oxford: Oxford University Press.

Réale, D., Reader, S.M., Sol, D., McDougall, P., \& Dingemanse, N. (2007). Integrating animal temperament within ecology and evolutionary biology. Biological Reviews, 82, 291-318.

Rebok, G.W., Smith, C.B., Pascualvaca, D.M., Mirsky, A.F., Anthony, B.J. et al. (1997). Developmental changes in attentional performance in urban children from eight to thirteen years. Child Neuropsychology, 3, 28-46.

Rosati, A.G., Stevens, J.R., Hare, B., \& Hauser, M.D. (2007). The evolutionary origins of human patience: temporal preferences in chimpanzees, bonobos, and human adults. Current Biology, 17, 1663-1668.

Rothbart, M.K., Ahadi, S.A., Hershey, K., \& Fisher, P. (2001). Investigations of temperament at three to seven years: the Children's Behavior Questionnaire. Child Development, 72, 1394-1408.

Rothbart, M.K., \& Bates, J.E. (2006). Temperament. In N. Eisenberg, W. Damon \& R.M. Lerner (Eds.), Handbook of child psychology: Vol. 3. Social, emotional, and personality development (6th edn., pp. 99-166). Hoboken, NJ: John Wiley \& Sons.

Rothbart, M.K., \& Derryberry, D. (1981). Development of individual differences in temperament. In M.E. Lamb (Ed.), Advances in developmental psychology, Vol. 1 (pp. 37-86). Hillsdale, NJ: Erlbaum.

Rothbart, M.K., Derryberry, D., \& Hershey, K. (2000). Stability of temperament in childhood: laboratory infant assessment to parent report at seven years. In V.J. Molfese \& D.L. Molfese (Eds.), Temperament and personality development across the life span (pp. 85-119). Hillsdale, NJ: Erlbaum.

Stevens, J.R., Rosati, A.G., Ross, K.R., \& Hauser, M.D. (2005). Will travel for food: spatial discounting and reward magnitude in two New World monkeys. Current Biology, 15, 1855-1860.

Thompson, C., Barresi, J., \& Moore, C. (1997). The development of future-oriented prudence and altruism in preschoolers. Cognitive Development, 12, 199-212.

Torigoe, T. (1985). Comparison of object manipulation among 74 species of nonhuman primates. Primates, 26, 182-194.
Uher, J., Asendorpf, J.B., \& Call, J. (2008). Personality in the behaviour of great apes: temporal stability, cross-situational consistency and coherence in response. Animal Behaviour, 75, 99-112.

Visalberghi, E., \& Limongelli, L. (1994). Lack of comprehension of cause-effect relations in tool-using capuchin monkeys (Cebus apella). Journal of Comparative Psychology, 108, $15-22$.

Vlamings, P.H.J.M., Hare, B., \& Call, J. (2010). Reaching around barriers: the performance of the great apes and 3-5year-old children. Animal Cognition, 13, 273-285.

Weiss, A., King, J.E., \& Figueredo, A.J. (2000). The heritability of personality factors in chimpanzees (Pan troglodytes). Behavior Genetics, 30 (3), 213-221.

Wellman, H.M., Lane, J., LaBounty, J., \& Olson, S.L. (2011). Observant, nonaggressive temperament predicts theory of mind development. Developmental Science, 14, 319-326.

Wobber, V., Hare, B., Herrmann, E., Wrangham, R., \& Tomasello, M. (2014). Differences in the early cognitive development of children and great apes. Developmental Psychobiology, 56, 547-573.

Yerkes, R.M., \& Yerkes, A.W. (1936). Nature and conditions of avoidance (fear) responses in chimpanzees. Journal of Comparative Psychology, 21, 53-66.

Zelazo, P.D., Mueller, U., Frye, D., \& Marcovitch, S. (2003). The development of executive function in early childhood. Monographs of the Society for Research in Child Development, 68 (3, Serial No. 274).

Zhou, Q., Chen, S.H., \& Main, A. (2012). Commonalities and differences in the research on children's effortful control and executive function: a call for integrated model of selfregulation. Child Development Perspectives, 6, 112-121.

Zhou, Q., Hofer, C., Eisenberg, N., Reiser, M., Spinrad, T. et al. (2007). The developmental trajectories of attention focusing, attentional and behavioral persistence, and externalizing problems during school-age years. Developmental Psychology, 43 (2), 369-385.

Received: 16 February 2014

Accepted: 16 September 2014

\section{Supporting Information}

Additional Supporting Information may be found in the online version of this article:

Figure S1: Survival functions for tendency to approach a novel object

Figure S2: Survival functions for tendency to inhibit a response that had been previously successful 